\title{
Polyneuropathy Quality Measurement Set
}

\author{
Quality Improvement in Neurology
}

Brian C. Callaghan, MD, Carmel Armon, MD, MSc, MHS, Vera Bril, MD, Lindsay Colbert, MA, William S. David, MD, PhD, David R. Del Toro, MD, Kenneth Fink, MD, MPH, Lyell K. Jones, Jr., MD, Robert Kleemeier, Leslie C. MacGregor, VMD, PhD, JD, Amy Bennett, JD, and Anant Shenoy, MD

Neurology ${ }^{\circledR}$ 2022;98:22-30. doi:10.1212/WNL.0000000000013037

Peripheral neuropathy affects $\sim 5 \%$ of the population and diabetes is the most common cause. ${ }^{1}$ Diabetic neuropathy often leads to pain, but clinicians do not always address neuropathic pain with their patients. ${ }^{1,2}$ Given the effect of painful diabetic neuropathy (PDN) on patients' quality of life, appropriate treatment of this prevalent condition is essential. ${ }^{1}$ To increase the delivery of effective management for patients with PDN, the American Academy of Neurology Institute (AANI) published a guideline on the treatment of PDN in 2011, and recently updated this guideline. ${ }^{1}$

The AANI also provides quality measures for individual physicians and clinicians, as well as treatment teams or practices to implement. The AANI's "Practice guideline update: Oral and topical treatment of painful diabetic polyneuropathy" posed a unique opportunity to simultaneously develop quality measures that could quantify how often guideline statements are implemented in practice while also evaluating potential new quality measures that would directly track patient care and outcomes. ${ }^{1}$ Based on a meta-analysis, the practice guideline revealed that the medication classes with the highest efficacy for PDN are gabapentinoids, serotonin norepinephrine reuptake inhibitors, tricyclic antidepressants, and sodium channel blockers. ${ }^{1}$ Furthermore, topical, nontraditional, and nonpharmacologic interventions are available. ${ }^{1}$ Based on the considerable potential harms of opioids, the guideline recommends against starting opioids, including tramadol and tapentadol, for PDN, and recommends offering the option of a safe taper off opioids for those already taking them. ${ }^{1}$

In concert with this guideline, the AANI formed a multidisciplinary work group tasked with identifying and developing process measures whose specifications stemmed from the updated diabetic neuropathy guideline statements as well as potential outcome measures that could apply to all polyneuropathy populations, not limited to diabetic neuropathy. These measures complement the AANI's distal symmetric polyneuropathy quality measurement set, which was released in 2014 and reaffirmed in 2019, and are not meant to be comprehensive measures reflecting all of the important aspects of the care of patients with polyneuropathy. ${ }^{3}$

\section{Opportunities for Improvement}

Opportunities to improve the care of patients with polyneuropathy exist. First, neuropathic pain is often not discussed during clinic visits. ${ }^{4}$ Even when pain is discussed, patients are often not treated. ${ }^{4}$ Furthermore, recent studies indicate that current treatment practice patterns are suboptimal, with a high frequency of opioid therapy and a low frequency of guidelineconcordant medications. ${ }^{5-7}$ Another opportunity to improve care is to address health care
Correspondence

American Academy

of Neurology

quality@aan.com

\section{RELATED ARTICLE}

Special Article

Oral and Topical

Treatment of Painful

Diabetic Polyneuropathy:

Practice Guideline Update

Summary: Report of the

AAN Guideline

Subcommittee

Page 31

AMERICAN ACADEMY OF NEUROLOGY。

From the Department of Neurology (B.C.C.), University of Michigan, Ann Arbor; Department of Neurology (C.A.), Tel Aviv University Sackler School of Medicine, Israel; Division of Neurology (V.B.), Department of Medicine, Toronto General Hospital, Canada; The Foundation for Peripheral Neuropathy (L.C.); Buffalo Grove, IL; Department of Neurology (W.S.D.), Massachusetts General Hospital, Boston; Physical Medicine and Rehabilitation (D.R.D.T.), Medical College of Wisconsin, Milwaukee; Kamehameha Schools (K.F.), Honolulu, HI; Department of Neurology (L.K.J.), Mayo Clinic, Rochester, MN; Minnesota Neuropathy Association (R.K.), Eau Claire, WI; Neuropathy Action Foundation (L.C.M.), Santa Ana, CA; American Academy of Neurology (A.B.), Minneapolis, MN; and Division of Neurology (A.S.), Mount Auburn Hospital, Springfield, MA.

Go to Neurology.org/N for full disclosures. Funding information and disclosures deemed relevant by the authors, if any, are provided at the end of the article.

Approved by the Polyneuropathy Quality Measurement Work Group on February 1, 2021; by the AANI Quality Measure Subcommittee on February 9, 2021; by the AANI Quality Committee on March 3, 2021; and by the AANI Board of Directors on March 23, 2021. 


\section{Glossary}

AAN = American Academy of Neurology; AANI = American Academy of Neurology Institute; CMS = Centers for Medicare \& Medicaid Services; LOINC = Logical Observation Identifiers Names and Codes; NRS = Numerical Rating Scale; PDN = painful diabetic neuropathy; PHQ-9 = Patient Health Questionnaire-9 Item; VAS = Visual Analog Scale.

disparities based on race and ethnicity in regards to pain management. Studies indicate that discrepancies exist in diagnosis and comfort level with clinicians based on race and ethnicity. ${ }^{8}$

The work group developed 3 measures to address these known gaps (Table 1 and Figure 1). The AANI provides these measures for individual physicians and clinicians as well as treatment teams or practices to implement. Benchmarks for performance are not provided. Measure implementers are encouraged to benchmark performance and use their individual scores to identify areas of improvement and push towards improved performance in future measurement periods. Implementing too many measures at one time is burdensome and may prevent meaningful focus on improving practice. Opting to use 1 or 2 measures is encouraged to allow for narrow focus on enhancing care for the patients treated in areas that are most meaningful for these patients.

\section{Methods}

Details of the AANI's full measure development process are available online. ${ }^{9}$ This was a pilot project formed by the Quality Measure Subcommittee and Guideline Subcommittee to simultaneously develop updated guideline statements and complimentary quality measures. As a result, a modified process was piloted. A targeted call for multidisciplinary work group members was made to existing representatives of the AANI guideline update group. Once individuals willing to serve on both groups were identified, a request was made to identify additional neurologists, patients, and advocate participants from American Academy of Neurology (AAN) membership and other engaged specialty societies and patient advocacy organizations. The application process was managed by the nonvoting facilitator methodologist seated from the Quality Measurement Subcommittee. ${ }^{9}$ Potential work group member subject matter expertise and measure development experience was reviewed as well as disclosure statements prior to being seated on the work group. ${ }^{9}$ The AANI measure development process requires disclosure of industry relationships and other entities to avoid actual, potential, or perceived conflicts of interest. ${ }^{9}$ Work group members were instructed to abstain from voting on individual measure concepts if a conflict was present. $^{9}$

A medical librarian assisted the work group in conducting a literature search to identify relevant guidelines, systematic reviews, and meta-analyses containing evidence of gaps in care for patients with polyneuropathy or articles summarizing patient and care partner preferences. This is a more tailored literature search than one used to develop AANI guideline statements. This literature search identified 2,758 abstracts from EMBASE and MEDLINE. The literature search results were winnowed to 129 articles. Following review of the identified articles, new measure concept proposals were submitted by work group members, which were then ranked by work group members for priority in development ${ }^{9}$ (Table 2). Per the AANI's measure development process, work groups are encouraged to create a small number of meaningful measures based on strong evidence, feasibility, and gaps in care to prevent burden on reporting providers, create more robust data sets to effect quality improvement, and maintain rigorous external testing requirements. ${ }^{9}$ Following ranking, the work group met virtually to refine concepts and discuss which measures should be approved for public comment. The work group members discussed denominator, numerator, and exclusion specifications during these meetings with the nonvoting facilitator moderating conversations to ensure a robust consensus process. Following discussion, a vote was held on each measure concept. A majority vote from a quorum of work group members was required to advance the measure to public comment, and members with any potential conflicts of interest are instructed to abstain from voting.

A 30-day public comment period was held on 3 draft measures (one of which is a paired measure having 2 denominators and 2 numerators) simultaneously as the practice guideline update: treatment of painful diabetic polyneuropathy public comment period. Nine individuals commented. The AANI promotes the public comment period to members, payers, industry partners, involved specialty societies, and patient advocacy organizations. During this comment period, there were fewer comments than anticipated based on prior AANI quality measure public comment periods, and this may be in part due to the ongoing public health emergency. Most comments received were made by neurologists. Comments received were important to the refinement of measure concepts.

Following review of individual comments on each measure concept, the work group met to address the comments and discuss advancement of these measure concepts. The 3 measure concepts were edited in response to public comment and finalized (Figure 2). Then the work group, AANI's Quality Measure Subcommittee, Quality Committee, and Board of Directors voted and approved the measurement set. ${ }^{9}$ Although this article references neurologists, these measures can be utilized by any clinician managing PDN. 
Table 1 Polyneuropathy Quality Measurement Set

\begin{tabular}{|c|c|c|c|c|}
\hline Title & Numerator & Denominator & Required exclusions & Allowable exclusions \\
\hline $\begin{array}{l}\text { Avoidance of Opioid } \\
\text { Medications for } \\
\text { Patients With Painful } \\
\text { Diabetic Neuropathy }\end{array}$ & $\begin{array}{l}\text { Patients prescribed an } \\
\text { opioid medication in the } \\
\text { measurement period }\end{array}$ & $\begin{array}{l}\text { Patients with a diagnosis of } \\
\text { diabetic neuropathy }\end{array}$ & $\begin{array}{l}\text { Opioid prescription } \\
\text { from a different } \\
\text { clinician }\end{array}$ & $\begin{array}{l}\text { - Patients counseled on last visit of } \\
\text { the calendar year and agreement } \\
\text { reached to discontinue opioid } \\
\text { medication } \\
\text { - Patients receiving opioids in the } \\
\text { setting of a controlled/monitored } \\
\text { program in order to manage an } \\
\text { opioid dependency (e.g., a } \\
\text { methadone maintenance program) } \\
\text { - Patients with active diagnosis of } \\
\text { cancer during measurement period } \\
\text { - Patient admitted to hospice care or } \\
\text { patient at end of life }\end{array}$ \\
\hline
\end{tabular}

Pain Assessment and Assessment of pain

Follow-up for

Patients With

Diabetic Neuropathy

(paired measures)
Patients diagnosed with diabetic None neuropathy

- Patient declines or refuses to complete pain assessment on date of encounter

- Unable to complete pain assessment on date of encounter (for example, nonverbal with no care partner present, coma)

- Patient declines or refuses to complete pain assessment on date of encounter

- Unable to complete pain assessment on date of encounter (for example, nonverbal with no care partner present, coma) - Patient has contraindications to appropriate pain medications documented in their history - Patient has an allergy to appropriate pain medications documented in their history

- Patient has previously failed one medication from each class of appropriate pain medications on date of encounter

- Patient has other reason for pain in the feet (for example, plantar fasciitis, osteoarthritis) in their history - Patient report pain is well controlled on date of encounter

Reduction of Pain for Patients whose VAS or NRS Patients aged 18 years and older Patients With Polyneuropathy pain score for patient's feet at 12 months ( \pm 60 days) was improved from the index score

\section{diagnosed with}

polyneuropathy with associated neuropathic pain in the feet and a VAS $\geq 40$ or NRS $\geq 4$ at index visit
- Polyneuropathy with associated neuropathic pain with encounter

a VAS $\leq 39$ or NRS $\leq 3$ at $\bullet$ Unable to complete pain

index visit

- Patients who died

- Second VAS or NRS

score not collected at

12 months ( \pm 60 days)

- VAS or NRS pain is

not linked to foot pain partner present, coma)
- Patient declines or refuses to complete pain assessment on date of assessment on date of encounter (for example, nonverbal with no care

- Patient has contraindications to appropriate pain medications documented in their history

- Patient has an allergy to appropriate pain medications documented in the history

- Patient has previously failed one medication from each class of appropriate pain medications on date of encounter

Abbreviations: NRS = Numerical Rating Scale; VAS = Visual Analog Scale.

Full specifications and definitions available for free at aan.com/policy-and-guidelines/quality/quality-measures2/quality-measures/other/

The AANI measure development process requires a triennial review of measures to confirm that evidence remains current, to determine whether a gap in care remains for measurement, and to evaluate response to any measure implementation and testing data.' As a result, this measurement set should be viewed through an iterative lens and will be subject to change in future reviews. The measures developed are concepts that were identified as meaningful to patients, care partners, and clinicians, feasible to collect in practice, and present an opportunity to improve outcomes for patients over time. What is feasible and meaningful may change over time, and measures will be updated to reflect this evolution. 
Figure 1 Polyneuropathy Measurement Set by Measure Type Classification

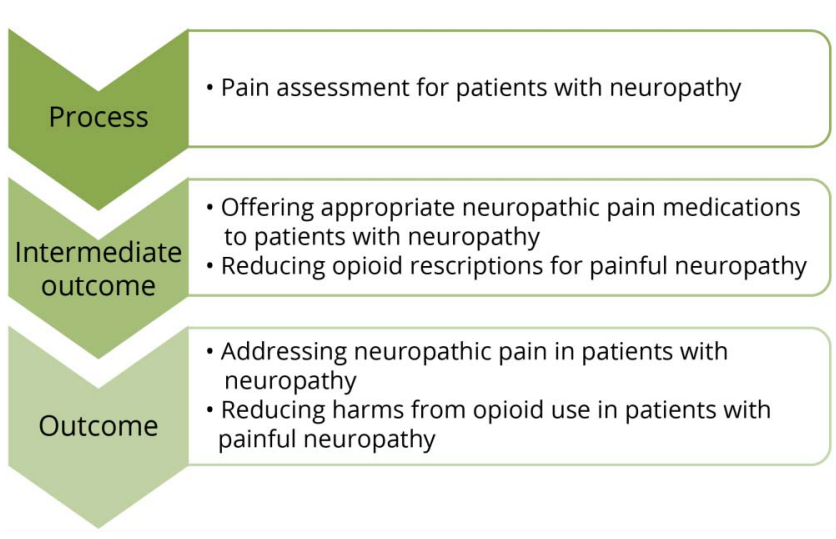

Quality measures can be classified into process, intermediate outcome, and outcome measures. Here we map the polyneuropathy quality measures developed by our work group to each of these types of quality measures.

\section{Results}

Three quality measures were developed (Table 1 and Figure 1 ). Full measurement specifications are available online at aan. $\mathrm{com} /$ policy-and-guidelines/quality/quality-measures2/quality-measures/other/.

\section{Avoidance of Opioid Medications for Patients With Diabetic Neuropathy}

Avoidance of Opioid Medications for Patients With Diabetic Neuropathy assesses the percentage of patients with diabetic neuropathy who were taking opioid medications. This is an inverse measure where a lower score is desirable. Zero percent performance is not the goal. Measure users should establish their baseline performance and use that as a benchmark for improvement in subsequent measurement periods.

This is an intermediate outcome measure intended to drive the reduction of opioid prescriptions for patients with DPN, as opioids are not indicated as a treatment for pain for patients with DPN. ${ }^{1}$ This measure is meant to limit new and existing opioid medications prescribed to patients with neuropathy by neurologists and encourages neurologists and pain specialists to discontinue and move away from opioid treatments because they have not been demonstrated to have long-term efficacy and have harmful effects for patients. ${ }^{1,10}$ Research indicates patients with DPN are being prescribed opioids. Patil et al. ${ }^{5}$ utilized a large health plan claims data set to determine that opioids were frequently used as first-line agents for DPN (33.33\%) compared to pregabalin (5.56\%). A prior assessment of Medicare data found that $62 \%$ of patients were prescribed a short-acting opioid. ${ }^{7} \mathrm{~A}$ nationally representative study of health care claims data found that opioids are commonly prescribed to patients with peripheral neuropathy; out of 14,426 patients with peripheral neuropathy, $65.9 \%$ received at least one opioid prescription. ${ }^{6}$ Even when excluding other chronic pain conditions, almost $9 \%$ of patients with polyneuropathy are prescribed opioids for more than 90 consecutive days. ${ }^{6}$ While not all of these opioid prescriptions were for neuropathic pain treatment, the magnitude of prescriptions in patients without other chronic pain diagnoses is concerning. The lack of long-term efficacy, high magnitude of adverse events, and frequent current use indicate the need for a measure to reduce opioid use in patients with polyneuropathy.

The work group developed several exclusions for this measure. Required exclusions prevent an individual from entering the denominator. For this measure, an opioid prescription from a different clinician is a required exclusion, and these patients are not included in calculation. Allowable exclusions differ and can only help measure performance. If a patient has an allowable exclusion but is found to meet the numerator, that patient is included in the count to meet the measure. There were multiple allowable exclusions created: patients counseled on last visit of the calendar year and agreement reached to discontinue opioid medication, patients receiving opioids in the setting of a controlled/monitored program to manage an opioid dependency (e.g., a methadone maintenance program), patients with active diagnosis of cancer during the measurement period, and patients admitted to hospice care or at end of life. The work group appreciates that there may be rare circumstances and patients who may benefit from opioids, but there is insufficient information available to define these cases for exclusion prospectively.

\section{Pain Assessment and Appropriate Treatment for Patients With Diabetic Neuropathy}

Pain Assessment and Appropriate Treatment for Patients With Diabetic Neuropathy is a paired measure concept. The numerator from measure 1 is used to define the denominator for measure 2 . There is a likelihood that only performance scores for numerator 2 would be reported if incorporated into an accountability program. The measure pair assesses percentage of patients diagnosed with diabetic neuropathy who were assessed for pain and had an appropriate medication offered if the pain assessment identified pain in their feet.

Pain is a frequent concern for patients with diabetes, but physicians do not always discuss this with patients, resulting in untreated pain. ${ }^{4}$ Furthermore, it was found that $12.5 \%$ of patients with diabetes and chronic painful peripheral neuropathy never reported their painful symptoms to their treating physician and $39.3 \%$ never received any treatment for their painful symptoms. ${ }^{4}$ Compared to White patients, there is evidence that African American and Hispanic patients report difficulty communicating and less comfort with their health care clinician and are less likely to be diagnosed with painful diabetic peripheral neuropathy. ${ }^{8}$ Therefore, a need exists to encourage assessment of pain in all patients with polyneuropathy, but especially in African American and Hispanic patients to reduce current disparities.

Pain assessment is defined as collection of a "pain in feet" score on a $0-10$ scale (Numerical Rating Scale $[$ NRS]) or a 0-100 scale (Visual Analog Scale [VAS]). This pain assessment is not 
Table 2 Ranked Measure Concepts

\begin{tabular}{|c|c|}
\hline Concept & $\begin{array}{l}\text { Average } \\
\text { ranking }\end{array}$ \\
\hline Pain: change in Visual Analog Scale score & 4.50 \\
\hline Falls & 4.63 \\
\hline $\begin{array}{l}\text { Sleep/fatigue } \\
\text { - Trouble falling or staying asleep } \\
\text { - Sleep quality } \\
\text { - Fatigue }\end{array}$ & 5.43 \\
\hline Quality of life & 6.38 \\
\hline $\begin{array}{l}\text { Balance or gait } \\
\text { - Dynamic standing or walking balance } \\
\text { - Linkage to physiotherapy or rehabilitation } \\
\text { - Patient's report on walking, how they feel walking } \\
\text { - Ability to walk unassisted }\end{array}$ & 6.71 \\
\hline Depression and anxiety & 8.29 \\
\hline $\begin{array}{l}\text { Daily life measure } \\
\text { - Missed work/school days } \\
\text { - Regular activities, activities of daily living, and hobbies affected } \\
\text { - Able to be independent with activities of daily living }\end{array}$ & 8.38 \\
\hline $\begin{array}{l}\text { Meaningful outcome identified by patient } \\
\text { - What are the } 1 \text { or } 2 \text { most critical outcomes that you would } \\
\text { like to focus on during treatment? }\end{array}$ & 9.00 \\
\hline Function: functional status scale results & 9.75 \\
\hline Loss of sensitivity in fingers or toes & 10.86 \\
\hline Ability to drive & 11.00 \\
\hline $\begin{array}{l}\text { Autonomic symptoms } \\
\text { - Constipation/diarrhea } \\
\text { - Urinary incontinence } \\
\text { - Sexual dysfunction } \\
\text { - Lightheadedness when standing suddenly } \\
\text { - Heart arrhythmias }\end{array}$ & 11.13 \\
\hline $\begin{array}{l}\text { Social function } \\
\text { - Socialization affected by neuropathy } \\
\text { - Satisfaction with relationships and social function }\end{array}$ & 11.86 \\
\hline Cost of therapies & 12.14 \\
\hline Unacceptable side effects of treatment & 12.33 \\
\hline Exercise & 13.17 \\
\hline Ability to concentrate: patient-reported outcome & 15.57 \\
\hline Abnormal electrophysiologic testing (EMG/NCV) & 15.63 \\
\hline Drug-induced neuropathy limits chemotherapy & 17.50 \\
\hline $\begin{array}{l}\text { Abnormal neurologic examination } \\
\text { - Loss of sensation } \\
\text { - Loss of temperature perception } \\
\text { - Muscle weakness or wasting }\end{array}$ & 17.71 \\
\hline Skin color changes & 18.43 \\
\hline $\begin{array}{l}\text { Biopsy results } \\
\text { - Change in intraepidermal small nerve fiber density (skin } \\
\text { biopsy) } \\
\text { - Abnormal nerve biopsy }\end{array}$ & 19.14 \\
\hline
\end{tabular}

Abbreviation: NCV = nerve conduction velocity

Work group members were encouraged to rank concepts, with \#1 representing the concept they believe is most meaningful to develop, \#2 being the second most meaningful to develop, et cetera, to \#24, representing the concept they believe is least meaningful to develop. Each number 1-24 was used only one time by each work group member. the same as the global pain assessment captured during most visits, but would be specific to pain in the feet for patients with polyneuropathy and documented with standardized scales. The work group notes that a clinical assessment of pain may include a verbal assessment, but numerical rating is indicated for this numerator. The requirement of collection of a pain score on a numerical scale of $0-10$ or $0-100$ such as the VAS or NRS is needed to drive comparable outcome data over time. The second portion of the paired measures requires detection of the denominator: "Patients diagnosed with diabetic neuropathy who had reported pain in their feet." The work group noted initial feasibility concerns that location of pain assessment is not standardized in electronic health records and use of the denominator would warrant chart review to confirm pain was in the patient's feet. The work group noted that measure implementation would be easier if codes were available to capture collection of the NRS and VRS.

Logical Observation Identifiers Names and Codes (LOINC) exist to capture common laboratory tests (e.g., severe acute respiratory syndrome coronavirus 2 [SARS-2]/coronavirus disease 2019 [COVID-19]), clinical documents (e.g., discharge summary), survey instruments (e.g., Patient Health Questionnaire-9 Item [PHQ-9]), and pain assessments from the electronic medical record. The AANI contacted LOINC to modify its existing pain assessment codes to make it easier to capture neuropathic pain assessments, which would facilitate implementation of this quality measure. This was the first collaboration of this nature, and the AANI hopes that additional collaborations will occur to create or standardize codes for neurology, thereby reducing the burden on physician and clinician documentation to meet quality measure specifications. As a result of this collaboration, LOINC code 80316-3 "Pain scale [type]" has been updated to incorporate the NRS and VRS as a possible scale. LOINC code 38204-4 "Pain primary locationReported" and 39111-0 "Body site" can be used to capture the location of assessment, in this case lower extremity, depending on how the data are reported. Capturing data using this standardized coding reduces physician and treatment team burden when implementing the measure. If LOINC codes are used, measure data can be gathered without chart reviews or changes to documentation style to capture performance via specific key phrases in clinical notes.

\section{Reduction of Pain for Patients With Polyneuropathy}

Reduction of Pain for Patients With Polyneuropathy is an outcome measure rather than an assessment of physician or clinician process. This measure directly assesses the health care outcomes for percentage of patients 18 years and older diagnosed with polyneuropathy with associated neuropathic pain in the feet whose VAS or NRS pain score for patient's feet at 12 months ( \pm 60 days) was improved from the index score.

This measure denominator differs from the other 2 measures in the set as it applies to patents diagnosed with polyneuropathy, not just DPN. 


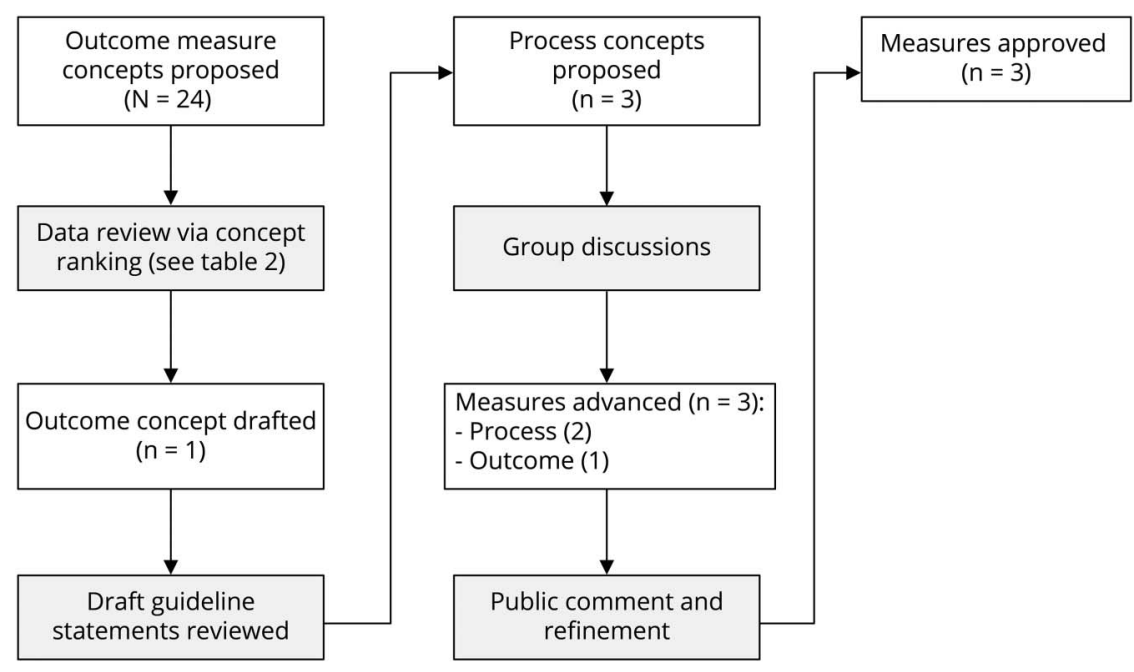

The American Academy of Neurology Quality Measure Process was used to generate the current polyneuropathy quality measures. Here we outline each step in this rigorous process to ensure high-quality measures are approved.

Improvement is defined as $30 \%$ reduction in scale score for the first index score in the patient record. The index score does not reset annually. The work group discussed measuring maintenance of pain vs improvement. The work group focused the numerator on improvement, as the goal is to drive neurologists to address pain. There is no expectation of $100 \%$ improvement, and the original index score is used through time to monitor improvement of $30 \%$ or greater, as evidence supports patients can expect a 30\%-50\% improvement over time with appropriate treatment. ${ }^{11}$ This measure captures pain levels at a specific point in treatment, and as a result has limitations, given that patients may be lost to the numerator when they are not seen at 12 months ( \pm 60 days). The work group notes that validated 10 -point or 100 -point pain scales are now standard in practice. As such, there will not be a burden placed on clinicians to collect new data for the measure denominator or numerator. LOINC codes further reduce clinician data burden collection pinpointing the pain location.

\section{Other Measures of Interest}

The AANI encourages work groups to not duplicate measures that already exist. The work group declined to create a polyneuropathy-specific falls measure given that a falls measure already exists for patients with a wide variety of neurologic conditions such as multiple sclerosis, stroke, movement disorders, and polyneuropathy. Measure implementers may want to consider use of the measures listed below for patients diagnosed with polyneuropathy:

- Patient-Reported Falls and Plan of Care. ${ }^{12}$ This AANIdeveloped measure captures the percentage of patients who reported a fall during the measurement period and had a plan of care documented.

- Quality of Life for Patients With Neurologic Conditions. ${ }^{13}$ This AANI-developed measure utilizes the
Patient-Reported Outcomes Measurement Information System (PROMIS) Global Health-10 to capture the percentage of patients whose quality-of-life assessment results are maintained or improved during the measurement period.

- Patients Screened or Treated for Depression. The work group reports that depression screening and treatment is of value and notes the following measures are approved for use in the 2021 Performance Year by Centers for Medicare \& Medicaid Services (CMS) in the Merit-based Incentive Payment System. ${ }^{14}$ This list is updated annually by CMS:

- Preventive Care and Screening: screening for depression and follow-up plan (CMS ID: QPP134; and CMS eCQM ID: CMS 2v10). ${ }^{14}$ This CMS measure assesses patients aged 12 years and older screened for depression on the date of the encounter or up to 14 days prior to the date of the encounter using an ageappropriate standardized depression screening tool and if positive, a follow-up plan is documented. The measure allows for a variety of screening tools to be used for the screening.

- Antidepressant Medication Management (CMS eCQM ID: CMS 128v9). ${ }^{14}$ This National Committee for Quality Assurance measure assesses the percentage of patients 18 years and older who were treated with antidepressant medication, had a diagnosis of major depression, and who remained on an antidepressant medication treatment.

- Depression Remission at 12 Months (CMS eCQM ID: CMS 159v9). ${ }^{14}$ This Minnesota Community Measurement outcome measure captures the percentage of adolescent patients 12-17 years of age and adult patients 18 years or older with major depression or dysthymia who reached remission at 12 months utilizing the PHQ-9. 
The work group hopes these quality measures provide tools for clinicians, treatment teams, and practices to drive meaningful quality improvement in the care of patients with polyneuropathy. Measure implementers are encouraged to select 1 or 2 measures that are most meaningful to their practice and patients, benchmark their performance, and implement quality improvement strategies to enhance patient care. Implementing too many measures at one time is burdensome and may prevent meaningful focus on improving practice. Measure implementers are also encouraged to benchmark performance and use their individual scores to identify areas of improvement and push towards improved performance in future measurement periods; benchmarks for performance are not provided. Adoption of these measures may lead to improved neuropathy pain control in this population with less opioid use, which has the potential to reduce the burden on current clinical practices.

These 3 quality measures will be submitted for consideration in the AANI's Axon Registry ${ }^{\circledR}$ to allow testing for feasibility and reliability. After testing, the work group hopes these measures might eventually be adopted by CMS and other payors for accountability programs. However, the work group does not recommend payors adopt these measures until they have been tested in clinical practice and risk adjustment strategies have been developed, as appropriate. These quality measures will be reviewed and evaluated every 3 years for retirement or update based on advances in evidence, feasibility concerns, and changes in gaps in care.

This quality measurement set had 2 novel approaches to the AANI's standard measurement development process. First, this was a pilot project formed by the Quality Measure Subcommittee and Guideline Subcommittee to simultaneously develop updated guideline statements and complimentary quality measures. The idea is that guideline statements inform the quality measurement process to drive quality improvement. Second, specific LOINC codes for pain in the feet were identified to better capture the intent of the quality measure and further reduce clinician data burden collection. The work group hopes these 2 approaches can be utilized as needed for future measurement set development.

\section{Examples of Using AANI Quality Measures in Practice}

Dr. Bautista works at a solo practice and decides to implement the Avoidance of Opioid Medications for Patients with Diabetic Neuropathy measure. Dr. Bautista reviews her opioid prescribing data for the past 3 months, removing patients with a current cancer diagnosis and those receiving hospice services, and sees that she is prescribing an opioid to $45 \%$ of her patients with PDN (baseline measure performance). Dr. Bautista's office manager outreaches her electronic health record vendor to ask that a best practice alert be added for patients diagnosed with DPN who are taking opioids. The best practice alert reminds Dr. Bautista that she should discuss alternative neuropathic pain treatments as well as the downsides of opioids for chronic noncancer pain. Dr. Bautista holds conversations with her patients and uses Internet resources to support conversations on alternate medications, including the AANI's guideline summary for patients. Options include oral, topical, and nonpharmacologic interventions that reduce neuropathic pain. She also discusses the downsides of opioids for chronic noncancer pain as summarized in the AAN position paper. ${ }^{15}$ After 4 months, Dr. Bautista recalculates her measure performance and sees an improvement: only $34 \%$ of her patients with PDN are now prescribed an opioid.

In a second example, Dr. Peterson is in an academic practice with 50 neurologists who implement the outcome measure assessing Reduction of Pain for Patients with Polyneuropathy. Dr. Peterson and team discover not all patients received pain screening, making monitoring of outcomes over time a challenge. Dr. Peterson discusses results with the department chair. The practice agrees to implement a planned visit model to better capture pain screening. ${ }^{16}$ Dr. Peterson's check-in staff hand out a laminated pain survey (1-10 scale) to every patient diagnosed with polyneuropathy at the time of arrival for an appointment. Nursing and medical assistants who room patients review responses and ask patients to identify the location of their pain. Staff then capture the patient scores and location of pain in the electronic medical record for Dr. Peterson. Staff also clean the pain survey handouts and return them to check-in staff for continued use, reducing the need for paper forms. Dr. Peterson reviews responses and examines patients during their visits. Dr. Peterson identifies ways to increase access to nonpharmacologic interventions for neuropathic pain such as cognitive behavioral therapy and mindfulness by partnering with the psychiatry department to identify the best referral process. After 6 months, results are reviewed; cognitive behavioral therapy is highly utilized, with good compliance, but mindfulness interventions are rarely used, with low compliance when initiated. As a result, Dr. Peterson assists in further streamlining the referral process for cognitive behavioral therapy. Dr. Peterson's staff confirm that $34 \%$ of his patients have had improved pain scores during the pilot period.

\section{Acknowledgment}

The work group thanks the American Association of Neuromuscular \& Electrodiagnostic Medicine, American Academy of Family Physicians, Foundation of Peripheral Neuropathy, Minnesota Neuropathy Association, and Neuropathy Action Foundation for their help identifying representatives and collaboration on the public comment for this project; and the staff at LOINC for their assistance identifying codes that will assist in standardized data collection for measures. All authors contributed equally to the development of the quality measurement set. B.C. Callaghan, A. Shenoy, and A. Bennett developed the manuscript and coordinated revisions with the remainder of the work group, who provided critical revisions and drafting input. 


\section{Study Funding}

The authors report no targeted funding.

\section{Disclosure}

B.C. Callaghan has received personal compensation for serving as an employee of University of Michigan and for serving as an employee of Ann Arbor Veterans Affairs; personal compensation in the range of $\$ 500-\$ 4,999$ for serving as a Consultant for Dynamed; personal compensation in the range of $\$ 500-\$ 4,999$ for serving as an Editor, Associate Editor, or Editorial Advisory Board member for American Academy of Neurology; personal compensation in the range of $\$ 10,000-\$ 49,999$ for serving as an expert witness for medico-legal work; personal compensation in the range of $\$ 50,000-\$ 99,999$ for serving as an expert witness for the Vaccine Injury Compensation Program; and personal compensation in the range of $\$ 500-\$ 4,999$ for serving as a grant reviewer with NIH. The institution of Dr. Callaghan has received research support from the American Academy of Neurology, JDRF, NIDDK, and VA CSRD. C. Armon has received personal compensation for serving as an employee of Shamir (Assaf Harofeh) Medical Center; personal compensation in the range of $\$ 10,000-\$ 49,999$ for serving as a consultant for Inbal-Israeli Government Insurance Company; personal compensation in the range of $\$ 5,000-\$ 9,999$ for serving as an Editor, Associate Editor, or Editorial Advisory Board member for the Journal of Neurologic Sciences; personal compensation in the range of $\$ 5,000-\$ 9,999$ for serving as an expert witness for individual attorney offices; and publishing royalties from a publication relating to health care. The institution of Dr. Armon has received research support from Eisai. V. Bril has received personal compensation in the range of \$500-\$4,999 for serving as a consultant for UCB; personal compensation in the range of $\$ 500-\$ 4,999$ for serving as a consultant for CSL; personal compensation in the range of \$500-\$4,999 for serving as a consultant for Octapharma; personal compensation in the range of $\$ 500-\$ 4,999$ for serving on a Scientific Advisory or Data Safety Monitoring Board for Takeda; personal compensation in the range of $\$ 500-\$ 4,999$ for serving on a Scientific Advisory or Data Safety Monitoring Board for Immunovant; personal compensation in the range of $\$ 500-\$ 4,999$ for serving on a Scientific Advisory or Data Safety Monitoring Board for Alexion; personal compensation in the range of $\$ 500-\$ 4,999$ for serving on a Scientific Advisory or Data Safety Monitoring Board for UCB; personal compensation in the range of $\$ 5,000-\$ 9,999$ for serving on a Scientific Advisory or Data Safety Monitoring Board for Akcea; personal compensation in the range of $\$ 500-\$ 4,999$ for serving on a Scientific Advisory or Data Safety Monitoring Board for Sanofi; personal compensation in the range of $\$ 500-\$ 4,999$ for serving on a Scientific Advisory or Data Safety Monitoring Board for Alnylam; personal compensation in the range of \$500-\$4,999 for serving on a Scientific Advisory or Data Safety Monitoring Board for CSL; personal compensation in the range of $\$ 500-\$ 4,999$ for serving on a Scientific Advisory or Data
Safety Monitoring Board for Argenx; personal compensation in the range of $\$ 5,000-\$ 9,999$ for serving on a Speakers Bureau for CSL; and intellectual property interests from a discovery or technology relating to health care. The institution of Dr. Bril has received research support from CSL, UCB, Argenx, Momenta, Immunovant, Alexion, Octapharma, and Takeda. L. Colbert reports no disclosures. W.S. David has received personal compensation in the range of $\$ 500-\$ 4,999$ for serving as an officer or member of the Board of Directors for Dysimmune Disorders foundation and personal compensation in the range of \$500-\$4,999 for serving as a rater for ALS Registry of Massachusetts; and publishing royalties from a publication relating to health care. D.R. Del Toro has received personal compensation in the range of $\$ 500-\$ 1,000$ for serving as a consultant and Advisory Board member for Ossur Americas. K. Fink has received personal compensation in the range of $\$ 10,000-\$ 49,999$ for serving as a colonel with Hawaii Air National Guard and personal compensation in the range of $\$ 10,000-\$ 49,999$ for serving as an expert witness with the State of Hawaii. L.K. Jones has received intellectual property interests from a publication relating to health care and has a noncompensated relationship on the Board of Directors of Mayo Clinic ACO that is relevant to AANI interests or activities. R. Kleemeier and L.C. MacGregor report no disclosures. A. Bennett is an employee of the American Academy of Neurology. A. Shenoy reports no disclosures. Go to Neurology.org/N for full disclosures.

\section{Publication History}

Received by Neurology June 10, 2021. Accepted in final form October 7, 2021.

\section{Appendix Authors}

\begin{tabular}{|c|c|c|}
\hline Name & Location & Contribution \\
\hline $\begin{array}{l}\text { Brian } \\
\text { Callaghan, } \\
\text { MD }\end{array}$ & $\begin{array}{l}\text { American Academy of } \\
\text { Neurology; Ann Arbor, MI }\end{array}$ & $\begin{array}{l}\text { Contributed to concept and } \\
\text { design, acquisition of data, } \\
\text { analysis and/or } \\
\text { interpretation of data, } \\
\text { drafting/revising the } \\
\text { manuscript, critical revisions } \\
\text { of the manuscript for } \\
\text { important intellectual } \\
\text { content, supervision, } \\
\text { including responsibility for } \\
\text { conduct and final approval }\end{array}$ \\
\hline $\begin{array}{l}\text { Carmel } \\
\text { Armon, MD, } \\
\text { MSc, MHS, } \\
\text { FAAN }\end{array}$ & $\begin{array}{l}\text { American Academy of } \\
\text { Neurology; Tel Aviv, Israel }\end{array}$ & $\begin{array}{l}\text { Contributed to acquisition of } \\
\text { data, analysis and/or } \\
\text { interpretation of data, } \\
\text { drafting/revising the } \\
\text { manuscript, critical revisions } \\
\text { of the manuscript for } \\
\text { important intellectual } \\
\text { content }\end{array}$ \\
\hline
\end{tabular}

Vera Bril, MD American Academy of Neurology; Toronto,

Contributed to acquisition of data, analysis and/or interpretation of data, drafting/revising the manuscript, critical revisions of the manuscript for important intellectual content 
Appendix (continued)

\begin{tabular}{lll}
\hline Name & Location & Contribution \\
\hline $\begin{array}{l}\text { Lindsay } \\
\text { Colbert, MA }\end{array}$ & $\begin{array}{l}\text { The Foundation for } \\
\text { Peripheral Neuropathy; } \\
\text { Buffalo Grove, IL }\end{array}$ & $\begin{array}{l}\text { Contributed to acquisition of } \\
\text { data, analysis and/or } \\
\text { interpretation of data, } \\
\text { drafting/revising the } \\
\text { manuscript, critical revisions } \\
\text { of the manuscript for } \\
\text { important intellectual } \\
\text { content }\end{array}$ \\
&
\end{tabular}

\begin{tabular}{ll}
\hline William S. & American Academy of \\
David, MD, & Neurology; Boston, MA
\end{tabular}
PhD

Contributed to acquisition of data, analysis and/or interpretation of data, drafting/revising the manuscript, critical revisions of the manuscript for important intellectual content

\begin{tabular}{lll}
\hline $\begin{array}{l}\text { David Del } \\
\text { Toro, MD }\end{array}$ & American Association of & $\begin{array}{l}\text { Contributed to acquisition of } \\
\text { data, analysis and/or } \\
\text { interpretation of data, } \\
\text { Electrodiagnostic }\end{array}$ \\
& Medicine; Milwaukee, WI & $\begin{array}{l}\text { drafting/revising the } \\
\text { manuscript, critical revisions } \\
\text { of the manuscript for } \\
\text { important intellectual } \\
\text { content }\end{array}$
\end{tabular}

Contributed to acquisition of data, analysis and/or interpretation of data, drafting/revising the manuscript, critical revisions of the manuscript for important intellectual content

Lyell K. Jones, American Academy of MD Neurology; Rochester, MN

Contributed to acquisition of data, analysis and/or interpretation of data, drafting/revising the manuscript, critical revisions of the manuscript for important intellectual content

\begin{tabular}{lll}
\hline $\begin{array}{l}\text { Robert } \\
\text { Kleemeier }\end{array}$ & $\begin{array}{l}\text { Minnesota Neuropathy } \\
\text { Association; Eau Claire, WI }\end{array}$ & $\begin{array}{l}\text { Contributed to acquisition of } \\
\text { data, analysis and/or } \\
\text { interpretation of data, } \\
\text { drafting/revising the } \\
\text { manuscript, critical revisions } \\
\text { of the manuscript for } \\
\text { important intellectual } \\
\text { content }\end{array}$ \\
\hline $\begin{array}{lll}\text { Leslie C. } \\
\text { MacGregor, }\end{array}$ & Feuropathy Action & $\begin{array}{l}\text { Contributed to acquisition of } \\
\text { data, analysis and/or } \\
\text { VMD, PhD, JD }\end{array}$ \\
& & $\begin{array}{l}\text { interpretation of data, } \\
\text { drafting/revising the } \\
\text { manuscript, critical revisions } \\
\text { of the manuscript for } \\
\text { important intellectual } \\
\text { content }\end{array}$ \\
& &
\end{tabular}

Appendix (continued)

\begin{tabular}{|c|c|c|}
\hline Name & Location & Contribution \\
\hline $\begin{array}{l}\text { Amy Bennett, } \\
\text { JD }\end{array}$ & $\begin{array}{l}\text { American Academy of } \\
\text { Neurology, Minneapolis, } \\
\text { MN }\end{array}$ & $\begin{array}{l}\text { Contributed to concept and } \\
\text { design, acquisition of data, } \\
\text { analysis and/or } \\
\text { interpretation of data, } \\
\text { drafting/revising the } \\
\text { manuscript, critical revisions } \\
\text { of the manuscript for } \\
\text { important intellectual } \\
\text { content, and supervision } \\
\text { including responsibility for } \\
\text { conduct and final approval }\end{array}$ \\
\hline $\begin{array}{l}\text { Anant } \\
\text { Shenoy, MD }\end{array}$ & $\begin{array}{l}\text { American Academy of } \\
\text { Neurology; Springfield, MA }\end{array}$ & $\begin{array}{l}\text { Contributed to concept and } \\
\text { design, acquisition of data, } \\
\text { analysis and/or } \\
\text { interpretation of data, } \\
\text { drafting/revising the } \\
\text { manuscript, critical revisions } \\
\text { of the manuscript for } \\
\text { important intellectual } \\
\text { content, and supervision } \\
\text { including responsibility for } \\
\text { conduct and final approval }\end{array}$ \\
\hline
\end{tabular}

\section{References}

1. Price R, Smith D, Franklin G, et al. Oral and topical treatment of painful diabetic polyneuropathy: practice guideline update summary: report of the AAN Guideline Subcommittee. Neurology. 2022;98(1):31-43.

2. Kiyani M, Yang Z, Charalambous LT, et al. Painful diabetic peripheral neuropathy: health care costs and complications from 2010 to 2015. Neurol Clin Pract. 2020;10(1):47-57.

3. England JD, Franklin G, Gjorvad G, et al. Quality improvement in neurology: distal symmetric polyneuropathy quality measures. Neurology. 2014;82(19):1745-1748.

4. Daousi C, MacFarlane IA, Woodward A, et al. Chronic painful peripheral neuropathy in an urban community: a controlled comparison of people with and without diabetes. Diabet Med. 2004;21(9):976-982.

5. Patil PR, Wolfe J, Said $\mathrm{Q}$, et al. Opioid use in the management of diabetic peripheral neuropathy (DPN) in a large commercially insured population. Clin J Pain. 2015;31(5):414-424

6. Callaghan BC, Reynolds E, Banerjee M, et al. Longitudinal pattern of pain medication utilization in peripheral neuropathy patients. Pain. 2019;160:592-599.

7. Pesa J, Meyer R, Quock TP, et al. Opioid utilization patterns among Medicare patients with diabetic peripheral neuropathy. Am Health Drug Benefits. 2013;6(4):188-196.

8. Eichholz M, Alexander AH, Cappelleri JC, et al. Perspectives on the impact of painful diabetic peripheral neuropathy in a multicultural population. Clin Diabetes Endocrinol. 2017;3:12.

9. Quality Measure Subcommittee. American Academy of Neurology Quality Measurement Manual 2019 Update.2020. Accessed April 26, 2021. aan.com/policy-and-guidelines/ quality/quality-measures2/how-measures-are-developed/

10. Dowell D, Haegerich TM, Chou R. CDC guideline for prescribing opioids for chronic pain: United States, 2016. MMWR Recomm Rep. 2016;65(RR-1):1-49.

11. Wong MC, Chung JW, Wong TK. Effects of treatments for symptoms of painful diabetic neuropathy: systematic review. BMJ. 2007;335(7610):87.

12. Martello J, Buchhalter J, Das RR, et al. Quality improvement in neurology: universal neurology quality measurement set: executive summary. Neurology. 2019;92(9):418-426.

13. Sico JJ, Sarwal A, Benish SM, et al. Quality improvement in neurology: neurology outcomes quality measurement set. Neurology. 2020;94(22):982-990.

14. Centers for Medicare \& Medicaid Services (CMS). Quality payment program: explore quality measures \& activities. Accessed April 26, 2021. qpp.cms.gov/mips/ explore-measures?tab=qualityMeasures\&py $=2021$

15. Franklin GM. Opioids for chronic noncancer pain: a position paper of the American Academy of Neurology. Neurology. 2014;83(14):1277-1284.

16. American Academy of Neurology. Patient reported outcomes: planned visit resources. Accessed April 26, 2021. AAN.com/PRO 


\section{Neurology}

\section{Polyneuropathy Quality Measurement Set: Quality Improvement in Neurology}

Brian C. Callaghan, Carmel Armon, Vera Bril, et al.

Neurology 2022;98;22-30

DOI 10.1212/WNL.0000000000013037

This information is current as of December 27, 2021

Updated Information \& Services

References

Subspecialty Collections

Permissions \& Licensing

Reprints including high resolution figures, can be found at: http://n.neurology.org/content/98/1/22.full

This article cites 13 articles, 6 of which you can access for free at: http://n.neurology.org/content/98/1/22.full\#ref-list-1

This article, along with others on similar topics, appears in the following collection(s):

All Health Services Research

http://n.neurology.org/cgi/collection/all_health_services_research All Practice Management

http://n.neurology.org/cgi/collection/all_practice_management Neuropathic pain

http://n.neurology.org/cgi/collection/neuropathic_pain

Information about reproducing this article in parts (figures,tables) or in its entirety can be found online at:

http://www.neurology.org/about/about_the_journal\#permissions

Information about ordering reprints can be found online:

http://n.neurology.org/subscribers/advertise

Neurology ${ }^{\circledR}$ is the official journal of the American Academy of Neurology. Published continuously since 1951, it is now a weekly with 48 issues per year. Copyright () 2021 American Academy of Neurology. All rights reserved. Print ISSN: 0028-3878. Online ISSN: 1526-632X.

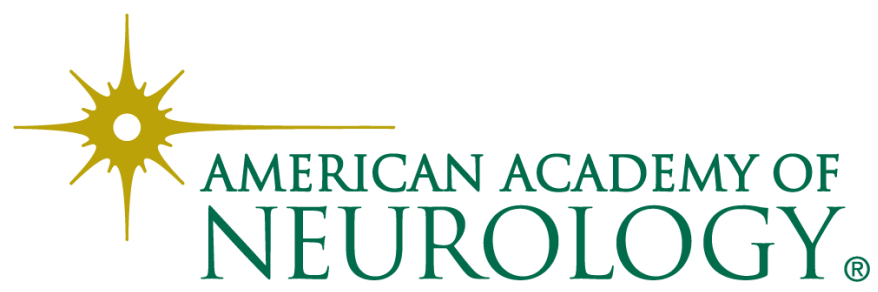

